\section{Editor-in-Chief \\ Barbara McLain - (retired Prof.) \\ University of Hawaii, USA}

The Israeli Journal of Aquaculture (IJA) is an interdisciplinary journal that is dedicated to sharing new research and tested applications of aquaculture

The IJA is devoted to scholarly articles for improved aquaculture practices and related industries

The IJA is a peer-reviewed, open-access, electronic journal

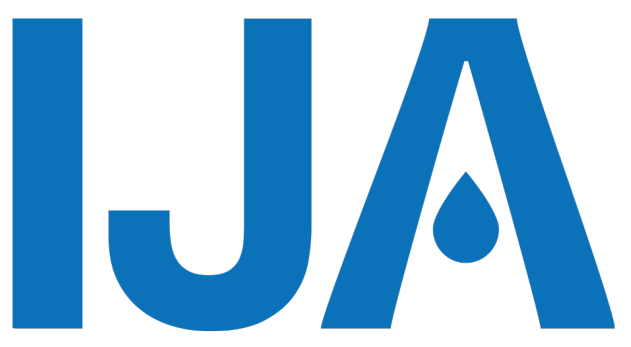

\section{The () Israeli Journal of Aquaculture}

An interdisciplinary online Open Access scientific journal

Published by the

\section{AquacultureHub}

A non-profit organization 501c3

http://www.aquaculturehub.org

in partnership with the

\section{University of Hawaii at Manoa} Library

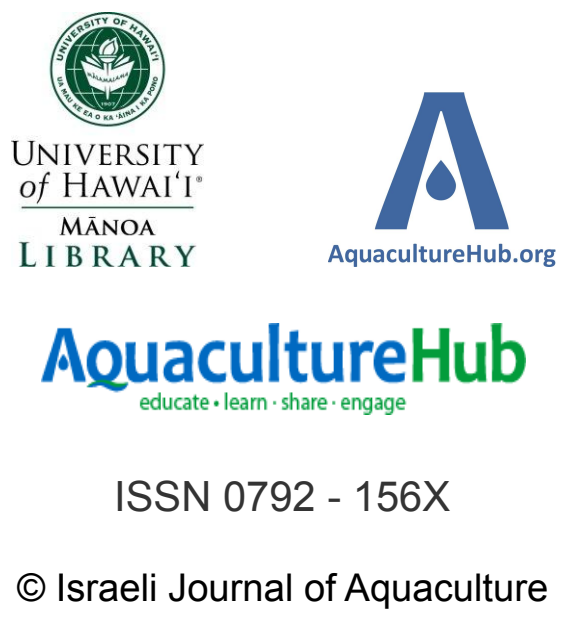




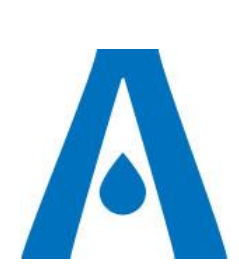

Produced by the AquacultureHub non-profit Foundation the IJA is an open-access, scientific journal, published on http://www.aquaculturehub.org/group/israelijournalofaq uaculturebamidgehija

To read papers free of charge, please register online at the above website.

Sale of IJA papers is strictly forbidden.

\title{
Effects of High Carbohydrate and Benfotiamine on the Growth and Feed Efficiency of Juvenile Nile Tilapia, Oreochromis niloticus
}

\section{Lauzon QD ${ }^{1,3}$, Canillo SDT², Tumbokon BLM ${ }^{2}$, Serrano AE, Jr..1,2*}

${ }^{1}$ Institute of Aquaculture, College of Fisheries and Ocean Sciences, University of the Philippines Visayas, Miagao 5023 Iloilo, Philippines

2 National Institute of Molecular Biology and Biotechnology, University of the Philippines Visayas, Miagao 5023 Iloilo, Philippines

3 Visayas State University-Tolosa, Tanghas, Tolosa 6503 Leyte, Philippines

Key words: benfotiamine; high carbohydrate diet; Nile tilapia; growth enhancer; feed stimulant

\begin{abstract}
This study aimed to evaluate the effects of a high carbohydrate diet (HC) alone and HC supplemented with benfotiamine (HCB), a human anti-diabetic supplement, on the growth performance of Nile tilapia fry, Oreochromis niloticus. A total of 180 Nile tilapia fry $(A W B=0.01 \mathrm{~g})$ were randomly distributed to 9 tanks and fed one of three experimental diets, namely, a control diet containing $15 \%$ carbohydrate; high carbohydrate diet (HC) containing $25 \%$ carbohydrate; and high carbohydrate diet (25\%) supplemented with $0.02 \%$ benfotiamine (HCB) for 8 weeks. Increasing corn starch in the diet from $15 \%$ (i.e. control diet) to $25 \%$ (i.e. HC diet) did not have any effect on the growth performance nor feed efficiency of the Nile tilapia. In contrast, Nile tilapia fed the HCB diet exhibited significantly the highest final average body weight, weight gain, specific growth rate, feed intake and whole-body lipid content and the most efficient FCR among the treatments. Results of the attractability tests showed that the HCB diet significantly attracted the most percentage of fish. In conclusion, the findings indicated that the Nile tilapia efficiently utilized an increase of carbohydrate from $15 \%$ to $25 \%$ and that dietary benfotiamine significantly increased the utilization of this diet, enhancing further its growth performance and feed utilization; benfotiamine also increased the attractability of the diet.
\end{abstract}

* Corresponding author. e-mail: serrano.gus@gmail.com 


\section{Introduction}

Carbohydrates are considered to be the most economical and excellent dietary energy source of fish due to their abundance and relatively low cost. Inclusion of carbohydrates in fish diets may not only enhance growth performance, but also provide metabolic intermediates for the synthesis of various biological compounds. Optimal inclusion in the diet could spare dietary protein as a source of energy subsequently channeled to growth. Furthermore, addition of carbohydrates in the diet results in the decrease of ammonia emission into the environment (Wilson, 1994; Kamalam et al. 2017; Hemre et al. 2002; Watanabe, 2003). However, fish have limited capacity to utilize dietary carbohydrates for energy purposes (Shiau, 1997; Polakof et al. 2012). Fish are considered diabetic as displayed by prolonged postprandial hyperglycemia after consuming diets containing high levels of carbohydrates (Moon, 2001); the underlying mechanisms of this observation are still poorly understood.

Thiamine plays a key role in cellular energy metabolism as it helps in the process of converting carbohydrates into energy (Balakumar et al. 2010). Benfotiamine, its analog, is a pro-vitamin B1 and a lipid-soluble derivative of thiamine having much higher absorption and bioavailability, at least five times greater plasma concentration, than the water-soluble form (Schreeb et al. 1997; Xie et al. 2014; Portari et al. 2013). It is considered as an anti-diabetic drug that once absorbed leads to significant increase in the thiamine, thiamine monophosphate, and thiamine diphosphate or thiamine pyrophosphate (TPP) levels in the blood and liver (Balakumar et al. 2010), in which, the latter is the active form of thiamine and considered crucial in intermediary metabolism of carbohydrates (Fattal-Valevski 2010). In mammals, pro-vitamin B1 stimulates glucose uptake by enhancing the glycolytic and glycogenetic capabilities, increasing mitochondrial glucose oxidation, promoting insulin synthesis, enhancing insulin-stimulated glucose disposal, and increasing the activity of GLUT-2, a glucose transporter (Seh-Hoon et al. 2009; Chung et al. 2014; Fraser et al. 2012). In aquatic animals, information regarding the beneficial effects of benfotiamine is extremely scarce.

Studies on the evaluation on the effects of benfotiamine on the growth performance in fish are very limited. The only work that evaluated benfotiamine in fish was on blunt snout bream (Megalobrama amblycephala) (Xu et al. 2017). Their results showed that fish fed a high carbohydrate diet supplemented with benfotiamine had higher protein efficiency ratio, nitrogen efficiency ratio and energy retention efficiency. In addition, fish showed relatively high values of whole-body lipid contents, tissue glycogen and lipid contents.

The present study aimed to investigate whether or not high carbohydrate diet is deleterious to the Nile tilapia, and whether supplementation of benfotiamine to this high carbohydrate diet could remedy or improve the growth performance of the Nile tilapia.

\section{Materials and Methods}

The experiments were conducted at the laboratory of the National Institute of Molecular Biology and Biotechnology (NIMBB), University of the Philippines Visayas, Miagao, Iloilo, Philippines.

\section{Experimental fish}

Healthy Nile tilapia fry (average body weight of $0.01 \mathrm{~g}$ ) were procured from the tilapia hatchery of Southeast Asian Fisheries Development Center, Aquaculture Department (SEAFDEC-AQD), Tigbauan, Iloilo, Philippines. The fry were brought to the laboratory of NIMBB, acclimatized and fed a control diet prior to the growth feeding trial.

\section{Diet preparation}

Three diets were formulated; the first diet contained $15 \%$ carbohydrate and served as the control, the second contained $25 \%$ carbohydrate $(\mathrm{HC})$ and the third contained $25 \%$ carbohydrate with $0.02 \%$ dietary benfotiamine incorporation (HCB); carboxymethylcellulose (CMC) was used for the adjustments in the amounts of corn starch and benfotiamine in the experimental diets. The composition of the diets is presented in Table 1.

Table 1. Composition of experimental diets fed to Nile tilapia fry. 


\begin{tabular}{|c|c|c|c|}
\hline \multirow[b]{2}{*}{ Feed } & \multicolumn{3}{|c|}{ Diets ( $\%$ composition) } \\
\hline & Control & $H C$ & $H C B$ \\
\hline Peruvian fish & 20.00 & 20.00 & 20.00 \\
\hline Soybean & 27.00 & 27.00 & 27.00 \\
\hline Shrimp meal & 18.00 & 18.00 & 18.00 \\
\hline Cornstarch & 15.00 & 25.00 & 25.00 \\
\hline Fish oil & 2.00 & 2.00 & 2.00 \\
\hline Soybean oil & 2.00 & 2.00 & 2.00 \\
\hline Vitamin mix & 2.00 & 1.50 & 1.50 \\
\hline Mineral mix & 2.00 & 1.50 & 1.50 \\
\hline $\mathrm{CMC}$ & 12.00 & 3.00 & 2.98 \\
\hline Benfotiamine & 0.00 & 0.00 & 0.02 \\
\hline TOTAL & 100.00 & 100.00 & 100.00 \\
\hline \multicolumn{4}{|c|}{ Proximate Analysis } \\
\hline Moisture & 10.08 & 13.73 & 11.99 \\
\hline Crude protein & 44.08 & 44.60 & 42.84 \\
\hline Crude lipid & 3.89 & 3.29 & 3.97 \\
\hline Crude ash & 11.26 & 9.80 & 10.08 \\
\hline Crude fiber & 2.94 & 2.36 & 1.88 \\
\hline Energy $(\mathrm{kcal} / \mathrm{kg})$ & 322.33 & 312.89 & 324.05 \\
\hline
\end{tabular}

HC: high carbohydrate; HCB: high carbohydrate supplemented with benfotiamine

Feeding Trial

A total of 180 Nile tilapia fry (ABW $0.01 \mathrm{~g}$ ) were randomly distributed into $9 \times 50 \mathrm{~L}$ plastic containers filled with $40 \mathrm{~L}$ freshwater (salinity of 5 parts per thousand, \%o) at a density of 20 fry/tank in a closed water recirculating system for 8 weeks and provided with continuous supply of aeration. The recirculating system consisted of three filters in different containers, namely, a fiber pad layer that filtered water coming from all experimental containers leading to a reservoir; water from the reservoir is pumped to a higher container of gravel and sand as another physical filter and allowed to pass through a biological filter composed of disinfected dead oyster shells by gravity; water from the biological filter is distributed again to the experimental containers.

Groups of fish from 3 randomly assigned tanks were fed with one of the 3 dietary treatments. Feeding was apparent ad libitum wherein the amount of feed to reach satiation was measured every first day of the week and was used as basis of the feeding rate for the next 7 days; this measurement was done repeatedly every week until the termination of the experiment. Feed was given 3 times daily at $0800 \mathrm{~h}, 1100 \mathrm{~h}$ and $1500 \mathrm{~h}$. Uneaten feeds and feces were siphoned off every morning before feeding, and in the afternoon before the last feeding of the day. About 30\% of the total water volume of the recirculating system was changed twice a week. Water temperature, $\mathrm{pH}$ and salinity were measured daily while nitrite and ammonia were monitored once a week. Sampling was done every $15^{\text {th }}$ day by bulk weighing of the fish per container. At the end of the feeding trial, samples were oven-dried at $80^{\circ} \mathrm{C}$ for $24 \mathrm{~h}$, homogenized and analyzed for proximate analyses (AOAC, 2000).

Response Parameters

Weight gain (WG), Specific Growth Rate (SGR), Feed Conversion Ratio (FCR) and \% Survival rate were calculated as follows:

Weight Gain $(\mathrm{g})=$ Final ABW-Initial ABW

Specific Growth Rate $=[\operatorname{Ln}($ Final ABW in g $)-\operatorname{Ln}($ Initial ABW in g) $] /($ No. of days $) * 100$

Feed Conversion ratio $=($ Total Feed Intake $) /($ Weight Gain $)$

Survival Rate $(\%)=($ Total no. of live tilapia) $/($ Total no. of tilapia stocked $) \times 100$

Statistical Analyses

Growth performance of Nile tilapia in different experimental groups were compared by One-way ANOVA $(p<0.05)$, using the SPSS statistical package version 16.0. Data is presented as mean \pm standard error mean (SEM) where each parameter was tested for normality of distribution and homogeneity of variances before performing ANOVA. Post- 
hoc analyses were done using Duncan's Multiple Range Test (DMRT) to identify differences between the independent factors.

Assessment of attractability of the three diets

Three rectangular glass tanks with multiple chambers were used to assess the attractability of the diets for Nile tilapia (Suresh et al. 2011). Each tank which measured $90 \mathrm{~cm} \times 30 \mathrm{~cm} \times 30 \mathrm{~cm}$ in length, width and height, respectively, was divided into three major chambers: acclimatization chamber, middle chamber and feeding chamber. A removable glass shutter separated the acclimatization and middle chambers. The feeding chamber was divided into three sub-chambers and each sub-chamber had an opening to allow free access of tilapia to experimental feeds that were placed in each chamber.

Six tests were done to assess attractability of the diets for 2 days with 3 simultaneous tests a day commencing at $0900 \mathrm{~h}$. Each tank was filled with $40 \mathrm{~L}$ freshwater ( 5 parts per thousand, \%o) and the tanks were set up in a closed room that received artificial light. Twenty Nile tilapia $(A B W=2 \mathrm{~g})$ were randomly stocked in the acclimatization chamber and acclimatized for $1 \mathrm{~h} .3 \mathrm{~g}$ of each diet was randomly placed in each of the 3 chambers. The shutter was removed 3 min after feed placement to allow access of tilapia to feeds. Feed preference was quantified by counting the number of tilapia in the feeding chamber at 1, 5, 10 min following the raising of the shutter. Percentage of tilapia per feeding chamber at different time intervals was calculated.

\section{Results}

Growth performance, feed efficiency and percent survival of O. niloticus fed the test diets for 60 days are presented in Table 2. Comparison of the response of the control group and that of the high carbohydrate group showed that increasing the dietary corn starch from $15 \%$ to $25 \%$ did not affect the growth and feed efficiency of the Nile tilapia. In contrast, benfotiamine supplementation resulted in significantly higher final average body weight (FABW), weight gain (WG), and specific growth rate (SGR). HCB also exhibited significantly better feed utilization than those fed the HC diet. No significant differences in survival rates among the three test groups were observed.

Table 2. Growth parameters, feed efficiency and survival of Nile tilapia fed the experimental diets. Mean values + SEM (standard error of the mean).

\begin{tabular}{lccccccc}
\hline Diet & $I_{A B W}(g)$ & $F_{A B W}$ & $\begin{array}{c}W G \\
(g)\end{array}$ & $\begin{array}{c}F I \\
(g)\end{array}$ & $\left.\begin{array}{c}S G R \\
(\% b w \text { day }\end{array}{ }^{-1}\right)$ & $F C R$ & Survival \\
\hline Control & 0.01 & $1.33 \pm 0.08^{\mathrm{b}}$ & $1.32 \pm 0.08^{\mathrm{b}}$ & $2.57 \pm 0.15^{\mathrm{b}}$ & $8.14 \pm 0.01^{\mathrm{b}}$ & $1.96 \pm 0.02^{\mathrm{a}}$ & $86.67 \pm 0.01^{\mathrm{a}}$ \\
$\mathrm{HC}$ & 0.01 & $1.23 \pm 0.03^{\mathrm{b}}$ & $1.22 \pm 0.03^{\mathrm{b}}$ & $2.42 \pm 0.49^{\mathrm{b}}$ & $8.02 \pm 0.00^{\mathrm{b}}$ & $1.99 \pm 0.00^{\mathrm{a}}$ & $83.33 \pm 0.01^{\mathrm{a}}$ \\
$\mathrm{HCB}$ & 0.01 & $2.07 \pm 0.15^{\mathrm{a}}$ & $2.06 \pm 0.22^{\mathrm{a}}$ & $3.51 \pm 0.12^{\mathrm{a}}$ & $8.88 \pm 0.01^{\mathrm{a}}$ & $1.71 \pm 0.08^{\mathrm{b}}$ & $90.00 \pm 0.01^{\mathrm{a}}$ \\
\hline
\end{tabular}

Superscripts indicate significant differences between diets $(p<0.05)$. Values are mean \pm SEM. IABW, initial average body eight; FABW, final average body weight; WG, weight gain; TIFI, total individual feed intake; SGR, specific growth rate; FCR, feed conversion ratio; Surv, \% survival; HC, high carbohydrate; HCB, high carbohydrate with benfotiamine.

The whole-body composition of Nile tilapia fed the experimental diets is presented in table 3. Tilapia receiving the HCB diet significantly exhibited the highest whole-body lipid content than that of the other groups. However, the HC group had significantly showed the highest whole-body protein content.

Table 3. Whole body composition (\% wet weight) of Nile tilapia fed the different experimental diets. Mean values \pm SEM (standard error of the mean).

\begin{tabular}{lrrrc}
\hline \multicolumn{1}{c}{ Diet } & $\%$ Moisture & $\%$ Ash & \%Crude Lipid & $\%$ Crude protein \\
\hline Control & $10.08 \% \pm 0.01^{\mathrm{b}}$ & $14.80 \% \pm 0.00^{\mathrm{a}}$ & $6.45 \% \pm 0.04^{\mathrm{b}}$ & $68.95 \% \pm 0.02^{\mathrm{b}}$ \\
HC & $13.73 \% \pm 0.00^{\mathrm{a}}$ & $14.69 \% \pm 0.00^{\mathrm{a}}$ & $8.13 \% \pm 0.07^{\mathrm{b}}$ & $70.67 \% \pm 0.00^{\mathrm{a}}$ \\
HCB & $7.99 \% \pm 0.00^{\mathrm{c}}$ & $12.55 \% \pm 0.00^{\mathrm{b}}$ & $12.14 \% \pm 0.07^{\mathrm{a}}$ & $66.34 \% \pm 0.00^{\mathrm{c}}$ \\
\hline
\end{tabular}

Superscripts indicate significant differences between diets $(p<0.05)$. Values are mean \pm SEM. HC, high carbohydrate; HCB, high carbohydrate with benfotiamine.

Results on the assessment of attractability of the experimental diets to the fish are presented in Table 4. The data showed that a significant percentage of fish were 
attracted to the HCB diet throughout the test period. At $10 \mathrm{~min}$, the percentage of the fish at the chamber where HCB was put increased further.

Table 4. Attractability of Nile tilapia to the experimental diets.

\begin{tabular}{lccc}
\hline \multicolumn{5}{c}{ Number of fish (\%) } \\
\hline Diet & $1 \mathrm{~min}$ & $5 \min$ & $10 \mathrm{~min}$ \\
\hline Control & $10.83 \pm 0.29^{\mathrm{b}}$ & $19.17 \pm 0.56^{\mathrm{b}}$ & $8.33 \pm 0.13^{\mathrm{b}}$ \\
HC & $7.50 \pm 0.07^{\mathrm{c}}$ & $14.16 \pm 0.48^{\mathrm{b}}$ & $3.33 \pm 0.10^{\mathrm{b}}$ \\
HCB & $22.50 \pm 0.06^{\mathrm{a}}$ & $28.33 \pm 0.39^{\mathrm{a}}$ & $34.17 \pm 0.78^{\mathrm{a}}$ \\
\hline
\end{tabular}

Means in the same column with different superscripts indicate differences between diets $(p<0.05)$. HC=high carbohydrate diet; $\mathrm{HCB}=$ high carbohydrate with benfotiamine.

\section{Discussion}

Fish have poor ability in utilizing carbohydrates and utilization varies among species (Wilson, 1994). Consumption of high carbohydrate diets causes deleterious effects on fish such as reduced growth rate often coupled with poor feed utilization and stress which later leads to immunosuppression (Hemre et al., 2002; Zhou et al. 2013) and to high rates of mortality. In this study, the \% survival for all fish groups were above $80 \%$. The high survival rate observed among fish fed diets containing high dietary carbohydrates in the present study was in agreement with a previous observation that tilapia can utilize carbohydrates at even higher levels (Wilson, 1994). Increasing the level of corn starch from $15 \%$ to $25 \%$ did not significantly affect the growth performance and feed utilization of the Nile tilapia. A study found that juvenile and adult Nile tilapia were able to utilize high carbohydrate diet (Boonanuntanasarn et al. 2018). In this study, the best growth performance was exhibited by tilapia fed with $30 \%$ carbohydrates compared to those fed carbohydrate-free and $50 \%$ carbohydrate diets. They have observed that the increase in hepatic and muscle glycogen, hepatic somatic index, and plasma metabolites were connected to the increase in dietary carbohydrates whereas no hyperglycemia and no changes in the body compositions were observed in fish fed $50 \%$ dextrin. These findings indicated that dietary carbohydrates were efficiently utilized as energy sources. The level of dietary protein (42-45\%) in the present study could have supported the growth of the Nile tilapia fry which exhibited an SGR of above 8.0 while those of Boonanuntanasarn et al. (2018) ranged from 3.0-4.3. High crude protein diet with high carbohydrate content was suitable for the Nile tilapia fry in the present study.

Thiamine has been reported to be essential for growth, and participates in energy metabolism as a cofactor in the form of thiamine pyrophosphate (Manzetti et al. 2014). Its lipid-soluble derivative is more absorbable, resulting in higher bioavailability. Benfotiamine is known to be an anti-diabetic drug but its importance and function in fish is still poorly understood. Normally, high dietary carbohydrates could reduce feed palatability; fish show higher sensitivity to testants (Morais, 2017) and feeding them with high carbohydrate diet could reduce feed intake. The results of the present study demonstrated that incorporation of dietary benfotiamine to high carbohydrate diet improved the growth performance and feed utilization of $O$. niloticus. In another study blunt snout bream fed with HCB (43\% carbohydrate) were observed to have significantly lower WG, SGR and TIFI compared to the control group (Xu et al. 2017). Furthermore, fish offered the HCB diet in their study exhibited high values of whole-body lipid contents, tissue glycogen, and plasma insulin levels. In addition, benfotiamine improved glucose tolerance of fish fed $\mathrm{HC}$ diet after a glucose load. In the present study, tilapia fed an HCB diet exhibited the significantly highest values for $F_{A B W}$, WG, SGR and TIFI among other treatments. In addition, incorporation of benfotiamine significantly enhanced the FCR. This suggests that thiamine enhances growth and intestinal enzyme activities in fish (Huang et al. 2007). In addition, the whole-body lipid content of fish fed the HCB diet was significantly higher than those fed the $\mathrm{HC}$ and control diets. This could be due to the action of benfotiamine in enhancing the activity of tranketolase effectively stimulating the pentose phosphate pathway (PPP) consequently enhancing fatty acid synthesis leading to body lipid accumulation (Hammes et al. 2003; Beltramo et al. 2008). 
Benfotiamine appears to possess protective roles in treating inflammatory diseases caused by metabolic stress (Yadav et al. 2010; Shoeb and Ramana, 2012). It reduces lipid peroxidation and protein damage in the muscles, provides protection to liver against oxidative damage and enhances expression and activities of anti-oxidative enzymes. (Gonçalves et al. 2019; Portari et al. 2016; Bozic et al. 2015). These protective properties of benfotiamine probably enhanced the overall health of the fish fed with high carbohydrate in this study as evident in the overall growth performance.

As fish feed constitutes a major bulk in the total cost of aquaculture production, feed additives such as attractants/stimulators are particularly important as they improve feed efficiency leading to reduced cost, specifically since they are usually supplemented in small amounts (Bai et al. 2015). Since the HCB diet was more attractive to the fish than either the control or $\mathrm{HC}$ diets in the present study, this demonstrated that benfotiamine also served as feed stimulant in trace amounts (0.02\%). This result was in agreement with that of Tai et al. (1999) in which thiamine is considered as a potential precursor for meat flavor. Since feed intake, weight gain, and feed conversion ratio are affected by feed stimulants (Papatryphon \& Soares, 2000), supplementing the feed with benfotiamine in the present study enhanced feed efficiency (i.e. reduced FCR). Benfotiamine should be further analyzed for its composition and efficacy, not only for juvenile tilapias but also for adult on-growing ones for a possible enhanced stimulatory effect on Nile tilapia.

In conclusion, increasing dietary carbohydrates from $15 \%$ to $25 \%$ did not have a negative effect on the growth performance of Nile tilapia juveniles. The incorporation of benfotiamine to the high carbohydrate (25\%) diet significantly enhanced its growth performance and feed utilization; the attractability of the diet to the fish was also enhanced.

\section{Acknowledgements}

The authors would like to thank the Philippine Council for Agriculture, Aquatic and Natural Resources Research and Development (PCAARRD) of the Department of Science and Technology (DOST) for the research grant; the Office of the Vice-Chancellor of Research and Extension of the University of the Philippines Visayas (UPV-OVCRE) for the publication grant and the Commission on Higher Education-K to 12 Program (CHED-K12) for the scholarship of Ms. Quenstein D. Lauzon. The authors are also grateful to Ms. Apple Gray Deallo, Mr. Arly Nim and Mr. Vicente Nim for their technical assistance.

\section{References}

AOAC., 2000. Official Methods of Analysis. Animal Feed. AOAC International, Arlington, TX, USA. Chapter 4, pp. 5-15.

Bai, S.C., Katya, K., Yun, H., 2015. Additives in aquafeed: an overview. In: Feed and Feeding Practices in Aquaculture, pp. 171-202.

Balakumar, P., Rohilla, A., Krishan, P., Solairaj, P., Thangathirupathi, A., 2010. The multi-faceted therapeutic potential of benfotiamine. G. Pharmacol.Res., 61(6):482488.

Beltramo, E., Berrone, E., Tarallo, S., Porta, M., 2008. Effects of thiamine and benfotiamine on intracellular glucose metabolism and relevance in the prevention of diabetic complications. Acta Diabetol., 45:131-141.

Boonanuntanasarn, S., Kumkhong, S., Yoohat, K., Plagnes-Juan, E., Burel, C., Marandel, L., Panserat, S., 2018. Molecular responses of Nile tilapia (Oreochromis niloticus) to different levels of carbohydrates. Aquaculture, 482:117-123.

Bozic, I., Savic, D., Stevanovic, I., Pekovic, S., Nedeljkovic, N., Lavrnja, I., 2015. Benfotiamine upregulates antioxidative system in activated BV-2 microglia cells. Frontiers in Cell Neurosci, 9(351).

Chung, K.M., Kang, W.Y., Dong, G.K., Hong, H.J., Lee, Y., Han, C.H., 2014. Antidiabetic effects of benfotiamine on an animal model of type 2 diabetes mellitus. Korean $\mathrm{J}$. Vet. Res.,54:21-26. 
Fattal-Valevski, A., 2010. Thiamine (Vitamin B10). J Evidence-Based Complementary \& Alternative Medicine, 16(1):12-20.

Fraser, D.A., Hessvik, N.P., Nikolic", N., Aas, V., Hanssen, K.F., Bøhn, S.K., Thoresen, G.H., Rustan, A.C., 2012. Benfotiamine increases glucose oxidation and downregulates NADPH oxidase 4 expression in cultured human myotubes exposed to both normal and high glucose concentrations. Genes Nutr.,7:459-469.

Gonçavales, A., Moreira, E.J.S., Portrari, G.V., 2019. Benfotiamine supplementation prevents oxidative stress in anterior tibialis muscle and heart. J Integr Med., $x x(x): x x x-$ xxx.

Hammes, H.P., Du, X., Edelstein, D., Taguchi, T., Matsumura, T., Je, Q., Lin, J., Bierhaus, A., Nawroth, P., Hannak, D., Neumaier, M., Bergfeld, T., Giardino, I., Brownlee, M., 2003. Benfotiamine blocks three major pathways of hyperglycemic damage and prevents experimental diabetic retinopathy. Nat. Med., 9:294-299.

Hemre, G.I.,Mommsen, T.P., Krogdahl, A., 2002. Carbohydrates in fish nutrition: effects on growth, glucose metabolism and hepatic enzymes. Aquac. Nutr., 8:175-194.

Huang, H.H., Feng, L., Liu, Y., Jiang, J., Jiang, W.D., Hu, K., Li, S.H., Zhou, X.Q., 2011. Effects of dietary thiamin supplement on growth, body composition and intestinal enzyme activities of juvenile Jian carp (Cyprinus carpio var. Jian). Aquac. Nutr. 17:233240.

Kamalam, B.S., Medale, F., Panserat, S., 2017. Utilisation of dietary carbohydrates in farmed fishes: New insights on influencing factors, biological limitations and future strategies. Aquaculture, 467:3-27.

Manzetti, S., van der Spoel, D., Zhang, J., 2014. Thiamin function, metabolism, uptake and transport. Biochemistry, 53(5):821-835.

Moon, T.W., 2001. Glucose intolerance in teleost fish: fact or fiction? Comp. Biochem. Physiol. B, 129:243-249.

Morais, S., 2017. The physiology of taste in fish: potential implications for feeding stimulation and gut chemical sensing. Reviews in Fisheries Science \& Aquaculture, 25(2):1-17.

Papatryphon, E., Soares, J.H., 2000. The effect of dietary feeding stimulants on growth performance of stripes bass, Morone saxtilis, fed-a-plant feedstuff-based diet. Aquaculture, 185:329-338.

Polakof, S., Panserat, S., Soengas, J.L., Moon, T.W., 2012. Glucose metabolism in fish: a review. J. Comp. Physiol. B.,182:1015-1045.

Portari, G.V., Vannucchi, H., Jordao, A.A., 2013. Liver, plasma and erythrocyte levels of thiamine and its phosphate esters in rats with acute ethanol intoxication: a comparison of thiamine and benfotiamine administration. Eur. J. Pharm. Sci., 48:799-802.

Portrari, G.V., Ovidio, P.P., Deminice, R., Jordão, A.A. Jr., 2016. Protective effect of treatment with thiamine or benfotiamine on liver oxidative damage in rat model of acute ethanol intoxication. Life Sci, 162;21-24.

Schreeb, K.H.,Freudenthaler, S., Vormfelde, S.V., Gundert-Remy, U., Gleiter, C.H., 1997. Comparative bioavailability of two vitamin B1 preparations: benfotiamine and thiamine mononitrate. European J Clin Pharmacol 1997, 52(4):319-320

Seh-Hoon, O., Rafal, P.W., Si-Hyun, B., Houda, D., Jung, Y.M., Liya, P., Brown, A., Petersen, B.E.,2009. Detection of transketolase in bone marrow-derived insulinproducing cells: benfotiamine enhances insulin synthesis and glucose metabolism. Stem Cells Dev., 18:37-45.

Shiau, S.Y., 1997. Uilization of carbohydrates in warmwater fish with particular reference to tilapia, Oreochromis niloticus X O. aureus. Aquaculture, 151(1-4):79-96.

Shoeb, M., Ramana, K.V., 2012. Anti-inflammatory effects of benfotiamine are mediated through the regulation of the arachidonic acid pathway in macrophages. Free Radical Biol Med, 52(1):182-190.

Suresh, A.V., Kumaraguru vasagan, K.P., Nates, S. 2011. Attractability and palatability of protein ingredients of aquatic and terrestrial animal origin and their practical value for blue shrimp, Litopenaeus stylirostris fed diets formulated with high levels of poultry byproduct meal. Aquaculture, 319: 132-140. 
Tai, C.Y., Yang, J., Ho, C.T., 1999. Effect of thiamin oxidation on thermal formation of meaty aroma compounds. In: Xiong, Y.L., Chi-Tang, H., Shahidi, F. (eds) Quality attributes of muscle foods. Springer, Boston, MA.

Watanabe, T., 2002. Strategies for further development of aquatic feeds. Fish. Sci.,68:242-252.

Wilson, R.P., 1994. Utilization of dietary carbohydrate by fish. Aquaculture,124:67-80.

Xie, F.F., Cheng, Z.N., Li, S.W., Liu, X.L., Guo, X., Yu, P., Gu, Z.K., 2014. Pharmacokinetic study of benfotiamine and the bioavailability assessment compared to thiamine hydrochloride. J. Clin. Pharmacol.,54:688-695.

Xu, C., Liu, W.B., Dai,Y.J., Jiang, G.Z., Wang, B.K., Li, X.F., 2017. Long-term administration of benfotiamine benefits the glucose homeostasis of juvenile blunt snout bream Megalobrama amblycephala fed a high-carbohydrate diet. Aquaculture, 470:7483.

Yadav, U.C.S., Kalariya, N.M., Srivastava, S. K., Ramana, K.V., 2010. Protective role of benfotiamine, a fat-soluble vitamin B1 analogue, in lipopolysaccharide-induced cytotoxic signals in murine macrophages. Free Radical Biol Medicine, 48(10):1423-1434.

Zhou, C.P., Ge, X.P., Liu, B., Xie, J., Miao, L.H., 2013. Effect of high dietary carbohydrate on the growth performance and physiological responses of juvenile wuchang bream, Megalobrama amblycephala. Asian-Australas J Anim Sci., 26(11):15981608. 